\title{
Detection of Legionella DNA by PCR of whole-blood samples in a mouse model
}

\author{
S. Aoki, ${ }^{1,2}$ Y. Hirakata, ${ }^{1,2}$ Y. Miyazaki, ${ }^{2}$ K. Izumikawa, ${ }^{2}$ K. Yanagihara, $^{2}$ \\ K. Tomono, ${ }^{2}$ Y. Yamada, ${ }^{1}$ T. Tashiro, ${ }^{2}$ S. Kohno ${ }^{2}$ and S. Kamihira ${ }^{1}$ \\ Department of Laboratory Medicine ${ }^{1}$ and Second Department of Internal Medicine ${ }^{2}$, Nagasaki \\ University School of Medicine, Nagasaki 852-8501, Japan
}

Correspondence

Y. Hirakata

hirakata@net.nagasaki-u.ac.jp

Received 13 June 2002

Accepted 23 December 2002

\begin{abstract}
A detection system for Legionella DNA in blood samples based on the PCR was developed and evaluated in A/J mice with experimentally induced Legionella pneumonia. Primers were designed to amplify a 106 bp DNA fragment of the 16S rRNA gene specific to Legionella species. The PCR system could detect clinically relevant Legionella species including Legionella pneumophila, Legionella micdadei, Legionella bozemanae, Legionella dumoffii, Legionella longbeachae, Legionella gormanii and Legionella jordanis. The sensitivity of the PCR system was $20 \mathrm{fg}$ extracted DNA. In the mouse model, the blood PCR was compared with results obtained by PCR on bronchoalveolar lavage fluid (BALF) samples, cultures of blood and BALF and detection of Legionella urinary antigen. Blood PCR was positive until 8 days after infection, while BALF PCR became negative on day 4 . These results indicate that PCR using blood samples may be a useful, convenient and non-invasive method for the diagnosis of Legionella pneumonia.
\end{abstract}

\section{INTRODUCTION}

Legionella pneumophila is one of the leading causes of bacterial pneumonia, particularly in susceptible individuals or the immunocompromised (El-Solh et al., 2001; Marston et al., 1997; Sopena et al., 1999). Legionella pneumonia is not always easy to diagnose, since clinical and radiographic features are often indistinguishable from those of pneumonias caused by other pathogens. Although serological examination has been one of the methods traditionally used for the diagnosis of Legionella pneumonia, paired sera are usually required. Moreover, as many as $25 \%$ of patients with Legionella pneumonia may fail to exhibit diagnostic antibody titres (Harrison \& Taylor, 1988). Culture of sputum or other respiratory samples such as a transtracheal aspirate (TTA) is another traditional method for the detection of Legionella species, reported to be specific and considered the 'gold standard' test (Yu, 1995). However, the sensitivity of the culture method has been reported to be as low as 10-60\% (Breiman \& Butler, 1998; Waterer et al., 2001). In addition, it is frequently difficult to obtain respiratory samples from patients with Legionella pneumonia, since most patients have a non-productive cough; physicians frequently need to obtain samples by invasive methods such as TTA or bronchoalveolar lavage (BAL). Furthermore, culture often fails to isolate the pathogens when patients have already been treated with antibiotics, even when such agents are not clinically potent.

Abbreviation: BALF, bronchoalveolar lavage fluid.
Recently, enzyme immunoassay (EIA) for the detection of Legionella antigen in urine has been used for diagnosis of Legionella pneumonia, with a reported sensitivity of 63-77\% (Benson et al., 2000; Dominguez et al., 1998; Stout \& Yu, 1997). PCR has also been used as a rapid diagnostic method, employing samples of BAL fluid (BALF) (Cloud et al., 2000; Jaulhac et al., 1998; Jonas et al., 1995; Matsiota-Bernard et al., 1994; Weir et al., 1998) or pleural effusion (Breiman \& Butler, 1998; Hirakata et al., 1996; Lo Presti et al., 2000). However, PCR detection of L. pneumophila using noninvasive specimens is preferable, particularly by family physicians and non-pulmonologists.

The aim of the present study was to examine the efficacy of PCR on blood samples as a rapid diagnostic method for Legionella pneumonia and to compare the results with those of PCR on BALF, cultures of blood and BALF samples and EIA to detect urinary antigen in a mouse model of Legionella pneumonia.

\section{METHODS}

Bacteria. L. pneumophila serogroup 1 ATCC $33152^{\mathrm{T}}$ (Philadelphia $1^{\mathrm{T}}$ ) was used for the animal experiments and for assessment of the sensitivity of PCR detection. The bacterial strains used for evaluation of specificity of PCR detection are summarized in Table 1.

Bacterial inoculum. L. pneumophila ATCC $33152^{\mathrm{T}}$ was stored until use at $-80{ }^{\circ} \mathrm{C}$ in Müller-Hinton broth containing $30 \%$ glycerol. A portion of the stock was cultured on buffered charcoal yeast extract (BCYE)- $\alpha$ agar (Oxoid) for 4 days at $37^{\circ} \mathrm{C}$. A single colony grown on BCYE- $\alpha$ agar was inoculated into $5 \mathrm{ml}$ buffered yeast extract (BYE) 
Table 1. Bacterial strains used for examination of PCR specificity

\begin{tabular}{|c|c|}
\hline Strain & PCR result \\
\hline L. pneumophila ATCC $33152^{\mathrm{T}}$ (serogroup 1) & + \\
\hline L. pneumophila ATCC 33153 (serogroup 1) & + \\
\hline L. pneumophila ATCC 33154 (serogroup 2) & + \\
\hline L. pneumophila ATCC 33155 (serogroup 3) & + \\
\hline L. pneumophila ATCC 33156 (serogroup 4) & + \\
\hline L. pneumophila ATCC 33215 (serogroup 5) & + \\
\hline L. pneumophila ATCC 33216 (serogroup 6) & + \\
\hline Legionella micdadei ATCC $33218^{\mathrm{T}}$ & + \\
\hline Legionella bozemanae ATCC $33217^{\mathrm{T}}$ & + \\
\hline Legionella dumoffii ATCC $33279^{\mathrm{T}}$ & + \\
\hline Legionella longbeachae ATCC 33469 (serogroup 1) & + \\
\hline L. longbeachae ATCC 33484 (serogroup 2) & + \\
\hline Legionella gormanii ATCC $33297^{\mathrm{T}}$ & + \\
\hline Legionella jordanis ATCC $33623^{\mathrm{T}}$ & + \\
\hline Klebsiella pneumoniae (clinical isolate) & - \\
\hline Pseudomonas aeruginosa NUS10 (clinical isolate) & - \\
\hline Mycoplasma pneumoniae MAC & - \\
\hline M. pneumoniae M129 & - \\
\hline M. pneumoniae $\mathrm{FH}$ & - \\
\hline Chlamydia pneumoniae TW- $183^{\mathrm{T}}$ & - \\
\hline C. pneumoniae KKpm-15 & - \\
\hline
\end{tabular}

broth (Difco Laboratories) and incubated under shaking at 130 r.p.m. for $24 \mathrm{~h}$ at $37^{\circ} \mathrm{C}$. A portion of the culture was inoculated into $5 \mathrm{ml}$ fresh BYE broth and incubated until the $\mathrm{OD}_{595}$ of the culture broth reached 0.5 . The bacterial suspension was centrifuged at 3000 r.p.m. for $15 \mathrm{~min}$ at $4{ }^{\circ} \mathrm{C}$ and the pellet was washed twice and resuspended in physiological saline. The bacterial suspension was adjusted to $1 \times 10^{9}$ c.f.u. $\mathrm{ml}^{-1}$ by turbidimetry.

Animal model of Legionella pneumonia. Male, 8-week-old, specific-pathogen-free A/J mice (Japan SLC Inc.) were used for all experiments. The mice were housed in a pathogen-free environment and received sterile food and water. These mice were inoculated intratracheally with L. pneumophila as described previously (Yanagihara ihara et al., 1997). Briefly, mice were anaesthetized with pentobarbital and then $0 \cdot 1 \mathrm{ml}$ bacterial suspension (approx. $10^{5}$ c.f.u. per mouse) was inoculated through the mouth into the trachea using the outer sheath of an intravenous needle (Top Co.). Body weight was measured on the days indicated after infection. The experimental protocol was approved by the Animal Care and Use Committee of Nagasaki University.

Sample collection. Urine samples were collected from mice housed in metabolic cages (Tecniplast). For sampling blood and BALF, five mice were selected at random on the days indicated and anaesthetized. An incision was made through the skin of the chest to expose the trachea, lungs and heart. Cardiac blood samples (about $800 \mu$ l per mouse) were obtained using a 26 -gauge needle and $1 \mathrm{ml}$ syringe containing a small amount of EDTA. A portion of blood was used for leukocyte counts. BALF was also obtained from these mice. For this purpose, the trachea was intubated with an intravenous catheter ( 3 Fr. Atom Co.), which was connected to a $1-\mathrm{ml}$ syringe. The lungs were washed three times with $0 \cdot 6 \mathrm{ml}$ cold $\mathrm{Ca}^{2+}$ - and $\mathrm{Mg}^{2+}$-free PBS (Gibco).

Recovery of $L$. pneumophila from BALF and blood samples. BALF and blood samples were cultured on BCYE- $\alpha$ agar containing vancomycin, polymyxin B and amphotericin B (WYO $\alpha$ agar; Eiken) and $5 \%$ sheep-blood agar (Nissui Pharmaceutical) for 7 days.
DNA extraction and PCR. DNA was extracted from blood samples with a Nucleo Spin blood kit (Clontech) and from BALF with a Nucleo Spin tissue kit (Clontech). Bacterial DNA was extracted with a DNeasy tissue kit (Qiagen). A 106-bp region of the Legionella 16S rRNAencoding gene was amplified using the $20 \mathrm{mer}$ primers LSP-GCG-S (sense, 5'-GCGGCTACCTGGCCTAATAC-3'; designed in this study) and Cp3.2 (antisense, 5'-CCAACAGTAAGTTGACATCG-3'; Jonas et al., 1995). PCR included initial denaturation at $94{ }^{\circ} \mathrm{C}$ for $4 \mathrm{~min}$ followed by 35 cycles of annealing at $56^{\circ} \mathrm{C}$ for $1 \mathrm{~min}$, extension at $72{ }^{\circ} \mathrm{C}$ for $1 \mathrm{~min}$ and denaturation at $94^{\circ} \mathrm{C}$ for $1 \mathrm{~min}$ and a final step of extension for $10 \mathrm{~min}$ at $72{ }^{\circ} \mathrm{C}$. For analysis of the PCR product, $2 \%$ agarose gel electrophoresis was performed with $10 \mu \mathrm{l}$ of the reaction solution and the DNA fragment was confirmed using ethidium bromide staining.

Detection of Legionella antigen in urine. Legionella antigen in urine was detected with Legionella urinary antigen EIAs from Binax and Biotest AG.

\section{RESULTS AND DISCUSSION}

\section{PCR sensitivity and specificity}

We first confirmed that the primers used in our study could detect as little as $20 \mathrm{fg}$ purified L. pneumophila DNA prepared in Tris/EDTA (Fig. 1). In another control study, it was possible to detect as little as $200 \mathrm{fg}$ L. pneumophila DNA in $200 \mu$ blood obtained from healthy volunteers. PCR assays using whole-blood samples have been considered difficult because of the presence of inhibitors in blood. PCR detection of Legionella in the serum or buffy coat has been reported previously (Aebischer et al., 1999; Lindsay et al., 1994; Murdoch \& Chambers, 2000; Murdoch et al., 1996, 1999), but not in whole-blood samples. Recently, commercially available kits for DNA extraction have facilitated PCR on whole-blood samples. The PCR product was detected in $L$. pneumophila serogroups 1-6, Legionella longbeachae serogroups 1 and 2 and five other Legionella species tested. On the other hand, PCR products were not detected for seven other bacterial strains unrelated to Legionella (Table 1). PCR amplification using primers for the mip gene has been widely

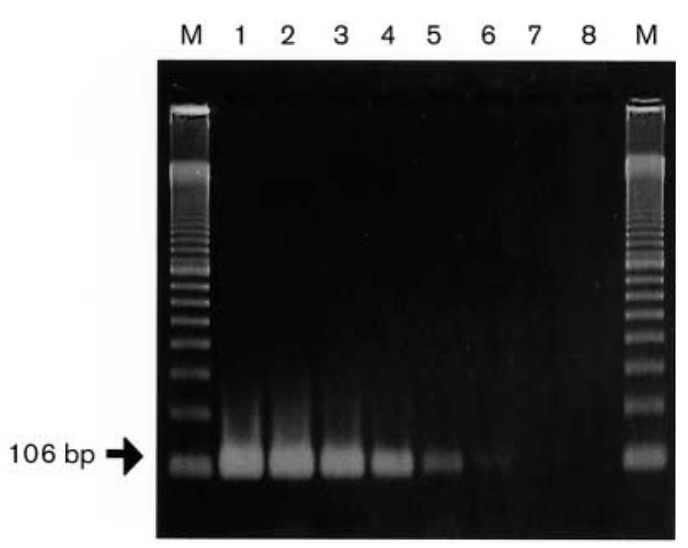

Fig. 1. Sensitivity of the PCR. L. pneumophila serogroup 1 ATCC $33152^{\top}$ DNA was purified and prepared in TE and $2 \mathrm{ng}-2 \mathrm{fg}$ was used for PCR. Lanes: M, molecular size marker; 1, 2 ng; 2, 200 pg; 3, 20 pg; 4, 2 pg; 5, 200 fg; 6, 20 fg; 7, 2 fg; 8, negative control (water). 
used, since these primers can detect most Legionella species, with the exception of Legionella geestiana (Ratcliff et al., 1998, 2001). For our PCR assay, we chose primers that amplify $106 \mathrm{bp}$ of the 16S rRNA gene, which may have certain advantages compared with methods reported previously. Firstly, amplification of the 16S rRNA gene may be more sensitive than that of the mip gene (Engleberg et al., 1989; Iwamoto et al., 1994) because multiple copies of the $16 \mathrm{~S}$ rRNA gene exist in bacteria. Furthermore, amplification of $5 \mathrm{~S}$ rRNA failed to detect several clinically relevant Legionella species, such as Legionella jordanis (Brieland et al., 1994). Our primers could detect most of the relevant species of Legionella, including $L$. jordanis, with high specificity.

\section{Features of experimentally induced pneumonia}

In previous studies (Brieland et al., 1994; Winn et al., 1982), animal models of Legionella pneumonia were established by incision of the trachea. In our mouse model of Legionella pneumonia, bacteria were inoculated intratracheally in a less invasive technique than those used previously. Therefore, the characteristics of infection in our mouse model resembled those of patients with Legionella pneumonia more closely than have other animal models. Acute pneumonia was confirmed by pathological examination of resected murine lungs stained with haematoxylin and eosin, as evident by cellular infiltration in alveoli and effusion. Body weight decreased gradually from $28.4 \pm 1.0 \mathrm{~g}$ (mean $\pm \mathrm{SD}$ ) at baseline to $20 \cdot 9 \pm 1.5 \mathrm{~g}$ at day 4 after infection. However, body weight subsequently recovered gradually and was $24 \cdot 4 \pm 1 \cdot 9$ $\mathrm{g}$ on day 13. As expected, acute pneumonia was associated with leukocytosis (basal leukocyte count, 2250; day 5, 11077 cells $\left.\mathrm{ml}^{-1}\right)$, but the count decreased to 3090 cells $\mathrm{ml}^{-1}$ on day 12 (Fig. 2). Our results were similar to those of Brieland et al. (1994) with regard to the severity of pneumonia. Their results in mice infected with Legionella showed that $L$. pneumophila grew exponentially in the lung during the 24$48 \mathrm{~h}$ post-inoculation and was gradually eliminated from the lungs during days 3-7 post-inoculation. Based on changes in body weight and leukocyte counts in our model, we concluded that pneumonia was most severe on days 3 to 5 after inoculation. In addition, the pathological changes in the lungs and inflammatory response were serious by $72 \mathrm{~h}$ after inoculation.

\section{Evaluation of diagnostic methods in a mouse model}

In the present study, we evaluated PCR on blood samples by comparing the results of this assay with the results of PCR on BALF samples, culture of blood and BALF samples and urinary antigen detection in a mouse model of Legionella pneumonia. Previous studies have reported the usefulness of PCR as a diagnostic test for Legionella pneumonia using respiratory specimens (Cloud et al., 2000; Hirakata et al., 1996; Jaulhac et al., 1998; Jonas et al., 1995; Lo Presti et al., 2000; Weir et al., 1998), with a sensitivity of $\geqslant 90 \%$ (Matsiota-Bernard et al., 1994). However, cough is nonproductive in most patients with Legionella pneumonia, and clinical symptoms deteriorate rapidly and severely. Therefore, it is often difficult to collect respiratory specimens using invasive techniques such as BALF. Consequently, specimens that could be collected non-invasively might be preferable. $L$. pneumophila was isolated from cardiac blood samples obtained on days 1 and 2, but could not be detected on or after day 3. On the other hand, the pathogen was recovered from BALF on days 1, 2 and 3, but was not detected on or after day 4. PCR assays of BALF samples were positive only on days 1, 2 and 3 after inoculation, while blood PCR remained positive until day 8 after infection and became negative on day 9. Legionella antigen in urine was positive from days 112 (Fig. 2) and was detected continuously up to day 30 by both the Biotest and Binax EIA. Therefore, in clinical cases, in addition to urinary antigen detection, whole-blood PCR may allow the diagnosis of Legionella pneumonia during the first several days after onset of the disease.

We performed further experiments to examine the relationship between positive urinary antigen and illness (data not shown). In these studies, we first established an oral-administration Legionella model by intraoesophageal inoculation of

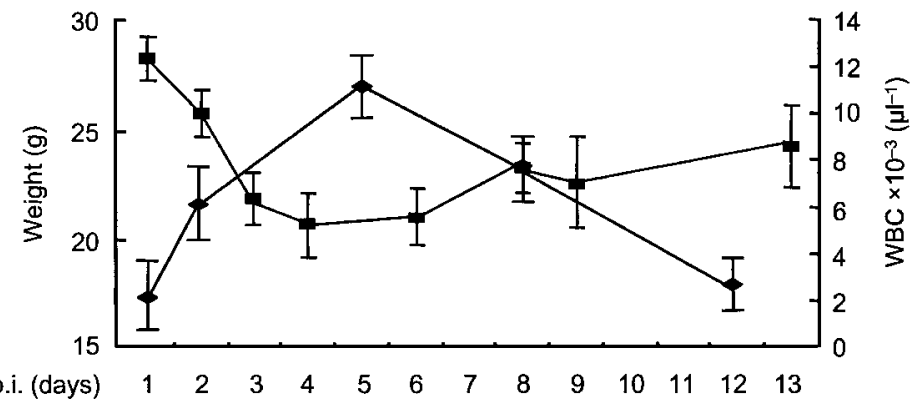

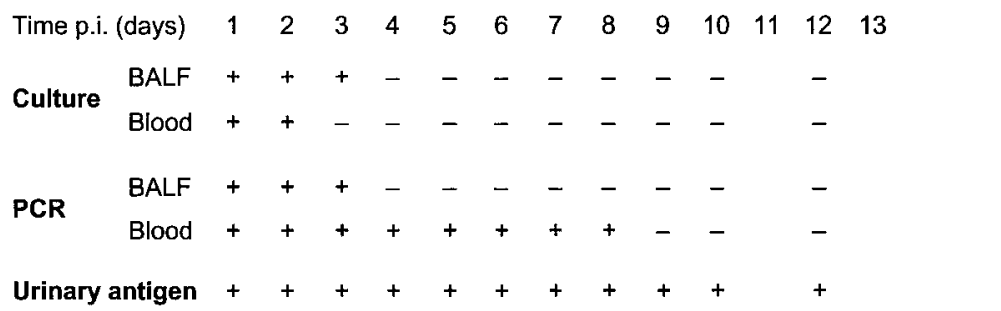

Fig. 2. Serial changes in body weight (-) and leukocyte count $(\bullet)$ in a mouse model of Legionella pneumonia. A/J mice were inoculated intratracheally with $L$. pneumophila ( $10^{5}$ c.f.u. per mouse) and body weight and peripheral leukocyte numbers were measured on the days indicated after infection. Data represent means \pm SD. WBC, Whole-blood count; p.i., postinoculation. Moreover, blood and BALF samples were cultured and used for PCR and urine samples were examined for Legionella antigen; results are shown. 
$6 \times 10^{6}$ c.f.u. L. pneumophila to A/J mice. The leukocyte count did not increase and weight loss was not observed in this model. Urinary antigen became positive at $6 \mathrm{~h}$ after inoculation and remained positive for 2 weeks after onset of infection. Blood PCR was negative throughout the test period. The chance of detecting urinary antigen would be minimal, as healthy humans are not tested for Legionella infections. These results, however, suggest that a person who drinks contaminated water may have a positive urinary antigen test even in the absence of clinical features of the disease. Another advantage of PCR compared with urinary antigen detection is that PCR gives the possibility of identifying Legionella to the species level in future by using the multiplex PCR method (Clark et al., 1993) or sequencing (Ratcliff et al., 2001).

In conclusion, in the present study, we have demonstrated that Legionella DNA could be detected by PCR in whole blood in a mouse model, suggesting that whole-blood PCR is a useful method for the diagnosis of Legionella pneumonia. Before whole-blood PCR can be applied to human samples, its specificity must be confirmed by Southern blotting or sequencing. Several studies have reported the usefulness of urine PCR (Helbig et al., 1999; Maiwald et al., 1995; Socan et al., 2000) as a diagnostic method. Further prospective studies of a large number of patients are required to examine the sensitivity and specificity and clinical impact of whole-blood PCR and to compare the assay with PCR on BALF and urine samples.

\section{ACKNOWLEDGEMENTS}

We thank Dr Naoyuki Miyashita, Department of Microbiology, Kawasaki Medical School, for supplying C. pneumoniae strains.

\section{REFERENCES}

Aebischer, C. C., Matter, L., Gaia, V. \& Aebi, C. (1999). Diagnosis by polymerase chain reaction of pneumonia caused by Legionella pneumophila in an immunocompetent child. Infection 27, 280-282.

Benson, R. F., Tang, P. W. \& Fields, B. S. (2000). Evaluation of the Binax and Biotest urinary antigen kits for detection of Legionnaires' disease due to multiple serogroups and species of Legionella. JClin Microbiol 38, 2763-2765.

Breiman, R. F. \& Butler, J. C. (1998). Legionnaires' disease: clinical, epidemiological, and public health perspectives. Semin Respir Infect 13, 84-89.

Brieland, J., Freeman, P., Kunkel, R., Chrisp, C., Hurley, M., Fantone, J. \& Engleberg, C. (1994). Replicative Legionella pneumophila lung infection in intratracheally inoculated $\mathrm{A} / \mathrm{J}$ mice. A murine model of human Legionnaires' disease. Am J Pathol 145, 1537-1546.

Clark, N. C., Cooksey, R. C., Hill, B. C., Swenson, J. M. \& Tenover, F. C. (1993). Characterization of glycopeptide-resistant enterococci from US hospitals. Antimicrob Agents Chemother 37, 2311-2317.

Cloud, J. L., Carroll, K. C., Pixton, P., Erali, M. \& Hillyard, D. R. (2000). Detection of Legionella species in respiratory specimens using PCR with sequencing confirmation. J Clin Microbiol 38, 1709-1712.

Dominguez, J. A., Gali, N., Pedroso, P., Fargas, A., Padilla, E., Manterola, J. M. \& Matas, L. (1998). Comparison of the Binax Legionella urinary antigen enzyme immunoassay (EIA) with the Biotest Legionella
Urine antigen EIA for detection of Legionella antigen in both concentrated and nonconcentrated urine samples. J Clin Microbiol 36, $2718-2722$.

El-Solh, A. A., Sikka, P., Ramadan, F. \& Davies, J. (2001). Etiology of severe pneumonia in the very elderly. Am J Respir Crit Care Med 163, 645-651.

Engleberg, N. C., Carter, C., Weber, D. R., Cianciotto, N. P. \& Eisenstein, B. I. (1989). DNA sequence of mip, a Legionella pneumophila gene associated with macrophage infectivity. Infect Immun 57, 1263-1270.

Harrison, T. G. \& Taylor, A. G. (1988). Timing of seroconversion in Legionnaires' disease. Lancet ii, 795.

Helbig, J. H., Engelstadter, T., Maiwald, M., Uldum, S. A., Witzleb, P. C. \& Luck, P. C. (1999). Diagnostic relevance of the detection of Legionella DNA in urine samples by the polymerase chain reaction. Eur J Clin Microbiol Infect Dis 18, 716-722.

Hirakata, Y., Hagiwara, S., Kawaguchi, K., Ishii, Y., Sugiyama, Y. \& Kitamura, S. (1996). Two coincidental isolated cases of Legionnaires' disease diagnosed by PCR and cured by combination therapy with clarithromycin and rifampicin. J Infect Chemother 2, 187-193.

Iwamoto, M., Koga, H., Kohno, S., Kaku, M. \& Hara, K. (1994). Detection of Legionella species by polymerase chain reaction. Infect Dis 7, 99-103.

Jaulhac, B., Reyrolle, M., Sodahlon, Y. K., Jarraud, S., Kubina, M., Monteil, H., Piemont, Y. \& Etienne, J. (1998). Comparison of sample preparation methods for detection of Legionella pneumophila in culturepositive bronchoalveolar lavage fluids by PCR. J Clin Microbiol 36, $2120-2122$.

Jonas, D., Rosenbaum, A., Weyrich, S. \& Bhakdi, S. (1995). Enzymelinked immunoassay for detection of PCR-amplified DNA of legionellae in bronchoalveolar fluid. J Clin Microbiol 33, 1247-1252.

Lindsay, D. S., Abraham, W. H. \& Fallon, R. J. (1994). Detection of mip gene by PCR for diagnosis of Legionnaires' disease. J Clin Microbiol 32, 3068-3069.

Lo Presti, F., Riffard, S., Jarraud, S., Le Gallou, F., Richet, H., Vandenesch, F. \& Etienne, J. (2000). Isolation of Legionella oakridgensis from two patients with pleural effusion living in the same geographical area. J Clin Microbiol 38, 3128-3130.

Maiwald, M., Schill, M., Stockinger, C., Helbig, J. H., Luck, P. C., Witzleb, W. \& Sonntag, H.-G. (1995). Detection of Legionella DNA in human and guinea pig urine samples by the polymerase chain reaction. Eur J Clin Microbiol Infect Dis 14, 25-33.

Marston, B. J., Plouffe, J. F., File, T. M., Jr, Hackman, B. A., Salstrom, S.-J., Lipman, H. B., Kolczak, M. S. \& Breiman, R. F. (1997). Incidence of community-acquired pneumonia requiring hospitalization. Results of a population-based active surveillance study in Ohio. The CommunityBased Pneumonia Incidence Study Group. Arch Intern Med 157, 1709-1718.

Matsiota-Bernard, P., Pitsouni, E., Legakis, N. \& Nauciel, C. (1994). Evaluation of commercial amplification kit for detection of Legionella pneumophila in clinical specimens. J Clin Microbiol 32, 1503-1505.

Murdoch, D. R. \& Chambers, S. T. (2000). Detection of Legionella DNA in peripheral leukocytes, serum, and urine from a patient with pneumonia caused by Legionella dumoffii. Clin Infect Dis 30, 382-383.

Murdoch, D. R., Walford, E. J., Jennings, L. C., Light, G. J., Schousboe, M. I., Chereshsky, A. Y., Chambers, S. T. \& Town, G. I. (1996). Use of the polymerase chain reaction to detect Legionella DNA in urine and serum samples from patients with pneumonia. Clin Infect Dis 23, 475-480.

Murdoch, D. R., Jennings, L. C., Light, G. J. \& Chambers, S. T. (1999). Detection of Legionella DNA in guinea pig peripheral leukocytes, urine and plasma by the polymerase chain reaction. Eur J Clin Microbiol Infect Dis 18, 445-447. 
Ratcliff, R. M., Lanser, J. A., Manning, P. A. \& Heuzenroeder, M. W. (1998). Sequence-based classification scheme for the genus Legionella targeting the mip gene. J Clin Microbiol 36, 1560-1567.

Ratcliff, R. M., Lanser, J. A., Heuzenroeder, M. W. \& Manning, P. A. (2001). Sequence-based genotype scheme for Legionella. In Legionella, pp. 237-242. Edited by R. Marre, Y. A. Kwaki, C. Bartlett, N. P. Cianciotto, B. S. Fields, M. Frosch, J. Hacker \& P. C. Luck. Washington, DC: American Society for Microbiology.

Socan, M., Kese, D. \& Marinic-Fiser, N. (2000). Polymerase chain reaction for detection of legionellae DNA in urine samples from patients with community-acquired pneumonia. Folia Microbiol (Praha) 45, 469-472.

Sopena, N., Sabria, M., Pedro-Botet, M. L. \& 7 other authors (1999). Prospective study of community-acquired pneumonia of bacterial etiology in adults. Eur J Clin Microbiol Infect Dis 18, 852-858.

Stout, J. E. \& Yu, V. L. (1997). Legionellosis. N Engl J Med 337, 682-687.
Waterer, G. W., Baselski, V. S. \& Wunderink, R. G. (2001). Legionella and community-acquired pneumonia: a review of current diagnostic tests from a clinician's viewpoint. Am J Med 110, 41-48.

Weir, S. C., Fischer, S. H., Stock, F. \& Gill, V. J. (1998). Detection of Legionella by PCR in respiratory specimens using a commercially available kit. Am J Clin Pathol 110, 295-300.

Winn, W. C., Jr, Davis, G. S., Gump, D. W., Craighead, J. E. \& Beaty, H. N. (1982). Legionnaires' pneumonia after intratracheal inoculation of guinea pigs and rats. Lab Invest 47, 568-578.

Yanagihara, K., Tomono, K., Sawai, T., Hirakata, Y., Kadota, J., Koga, H., Tashiro, T. \& Kohno, S. (1997). Effect of clarithromycin on lymphocytes in chronic respiratory Pseudomonas aeruginosa infection. Am J Respir Crit Care Med 155, 337-342.

Yu, V. L. (1995). Legionella pneumophila (Legionnaires' disease). In Principles and Practice of Infectious Diseases, 4th edn, pp. 2087-2097. Edited by G. L. Mandell, J. E. Bennett \& R. Doln. New York: Churchill Livingstone. 